\title{
Use of Alleviators to Reduce Toxicity of Chromium in Germination of Common Agricultural Crops
}

\author{
Muhammad Umar Hayyat ${ }^{1, *}$, Rashid Mahmood ${ }^{1}$, Sadia Akram$^{1}$, Zawar Haider ${ }^{1}$, Syed Tariq Rizwan $^{2}$, \\ Zafar Siddiq ${ }^{2}$, RabNawaz $^{1}$ \\ ${ }^{1}$ Sustainable Development Study Centre, GC University Lahore, Pakistan \\ ${ }^{2}$ Department of Botany, GC University Lahore, Pakistan
}

Copyright (C) 2015 Horizon Research Publishing All rights reserved.

\begin{abstract}
The effect of chromium on common agricultural crops (wheat, Indian mustard, sorghum, maize) was investigated and some alleviators were used to reduce chromium toxicity. Petri plate experiments were conducted in order to germinate seeds of crops. The results showed no reduction in germination up to $500 \mathrm{ppm}$ but gradual decrease was observed in higher concentrations. Germination was higher in Indian mustard as compared to wheat and sorghum, however maize exhibited maximum germination. The higher chromium concentration (1000 ppm) significantly inhibited germination, plumule and radicle length. Addition of alleviators (ammonium sulphate, calcium sulphate, calcium phosphate, potassium chloride, zinc sulphate) indicated reduction in chromium toxicity. The most effective alleviator was zinc sulphate. It may be concluded that the attenuation of chromium toxicity by alleviators addition is directly attributed to its regulation on germination, and their distribution at radicle and plumule length. The present study can be used as a tool to alleviate chromium toxicity to enhance the yield of common crops in soils contaminated by chromium.
\end{abstract}

Keywords Toxic Metal, Germination Inhibition, Toxicity Alleviation, Zinc Sulphate, Crop Yield

\section{Introduction}

Chromium is highly toxic metal which is present in many oxidation states but it is naturally stable in trivalent and hexavalent forms. It is carcinogenic and causes serious health problems to the ecosystem. Its presence in water and soil causes an alteration in nutrient composition [1], [11]. It is frequently used in leather treating, wood manufacture, carpet and electroplating, textile dyeing, pharmaceuticals and dairy industries. The risk of $\mathrm{Cr}$ transfer in the food chain from soil is high due to the uptake and accumulation by plants [3]. Chromium joins soil through natural paths and disturbs normal functioning of soil and plant development
[12]. It reduces root and shoot length, decrease rate of transpiration and photosynthesis, decrease plant biomass, lowers stomatal conductance, drops plant height etc [17]. Chromium decreases palisade number and parenchyma cells in plants, it also increases amount of vacuoles and electron thick matter alongside xylem and phloem walls [21].

The literature revealed that seed germination tests are important in heavy metal studies like chromium. Seed ability to germinate in chromium showed the level of tolerance for seeds [13], [18]. $\mathrm{Cr}$ is generally toxic to higher plants at $100 \mathrm{uM} \mathrm{kg} \mathrm{kf}^{-1}$ dry weight [8]. The concentration of $\mathrm{Cr}$ in tannery waste is about $20,000 \mathrm{ppm}$, about $1800 \mathrm{ppm}$ in sludge and $200 \mathrm{ppm}$ in composite effluent, and these are disposed of without any treatment in developing countries. In addition, the physicochemical analysis of tannery effluent showed that the effluent normally contains 100 to $200 \mathrm{mg} / \mathrm{l}$ of chromium. The presence of an excess amount of chromium beyond the tolerable limits makes the land unsuitable for crop growth and the fertility is also adversely affected by wastewater emanating from tanneries [14].

The reduction in chromium uptake by plant can occur by reactions with other ions, metallic, mineral surfaces and organic molecules [2]. Silicon, glutathione and phosphorous have been generally used to alleviate heavy metal stresses in plants such as glutathione is able to alleviate $\mathrm{Cr}$ toxicity in rice. Phosphorus is an essential macronutrient and competes with $\mathrm{Cr}$ for uptake. Phosphorus is taken up by plants in the form of phosphate ions present as dissolved inorganic phosphorus in the water column of soil particles [7]. The present study is designed to examine chromium toxicity on germination of common agricultural crops of Punjab, Pakistan. Alleviators (ammonium sulphate, calcium sulphate, calcium phosphate, potassium chloride and zinc sulphate) were used after that in order to improve germination by reducing toxicity. Laboratory experiment was conducted to investigate the impact of alleviators on germination, radicle and plumule length under $\mathrm{Cr}$ stress. This study will help in improving soil conditions affected by chromium toxicity and improving growth of crops. 


\section{Materials and Methods}

\subsection{Experiment 1: Effect of Chromium on Germination of Different Agricultural Crops}

Seeds of four common crops of Punjab Pakistan; wheat (Triticum aestivum L. CV. Uqaab-2000), maize (Zea mays L. CV. C1415), sorghum (Sorghum vulgare Pers CV. SSG-5000) and Indian mustard (Brassica juncea L. CV. 45J21) were collected from Punjab Seed Certification Department, Lahore. Selected seeds were stored in plastic bags and were used. The seeds were surface sterilized in a $2 \% \mathrm{H}_{2} \mathrm{O}_{2}$ solution for $10 \mathrm{~min}$, rinsed with distilled water for $20 \mathrm{~min}$, and washed with deionized water (three times). $\mathrm{K}_{2} \mathrm{Cr}_{2} \mathrm{O}_{7}$ was used as hexavalent chromium as $1000 \mathrm{mg}$ of $\mathrm{K}_{2} \mathrm{Cr}_{2} \mathrm{O}_{7}$ contains $353 \mathrm{mg}$ chromium.

The seeds were soaked in $0,25,50,100,200,500,600,700$, $800,900,1000 \mathrm{ppm}$ of chromium solutions at $25^{\circ} \mathrm{C}$ for 12 hours, shifted to petri plates for germination at $30^{\circ} \mathrm{C}$, and then to germination chamber (WGC-450) with photoperiod of $16 / 8 \mathrm{~h}$ (light/ dark) and light intensity of $225 \pm 15 \mu \mathrm{mol} \mathrm{m}^{-2}$ $\mathrm{s}^{-1}$. The light/dark temperatures were $30 / 22^{\circ} \mathrm{C}$, and relative humidity was $80 \%$. The solutions of respective chromium concentration were applied after alternative days. After seven days after germination, all the petri plates were taken out from germination chamber and germination percentage, plumule and radicle lengths were measured to evaluate chromium toxicity [22].

Rate of germination $\%=$ number of seeds germinated $/$ total number of seeds $\times 100$

\subsection{Experiment 2: Alleviation of Chromium Toxicity in Germination by the Use of Different Alleviators}

The surface sterilized seeds were soaked in $1000 \mathrm{ppm}$ chromium solution along with $200 \mathrm{ppm}$ solution of each alleviator (calcium sulfate, ammonium sulphate, potassium sulphate, potassium chloride, zinc sulphate) for 12 hours and shifted to petri plates for germination at $30^{\circ} \mathrm{C}$. Petri plates were shifted to a germination chamber (WGC-450) with photoperiod of $16 / 8 \mathrm{~h}$ (light/ dark) and light intensity of $225 \pm 15 \mu \mathrm{mol} \mathrm{m} \mathrm{m}^{-2} \mathrm{~s}^{-1}$. The light/dark temperatures were $30 / 22^{\circ} \mathrm{C}$, and relative humidity was $80 \%$. The solutions of each alleviator along with $1000 \mathrm{ppm}$ chromium were applied after alternative days. Again after seven days of germination, all the petri plates were taken out from germination chamber and germination percentage, plumule and radicle lengths were noted to evaluate alleviation in chromium toxicity [22].

\subsection{Statistical Analysis}

Statistical analysis was carried out using SPSS v.16. Mean and standard deviation of all treatments were calculated by using SPSS [23].

\section{Results}

\subsection{Effect of Chromium on Germination of Different Agricultural Crops}

The results delineate germination of different agricultural crops that was observed in different $\mathrm{Cr}$ concentrations. Chromium uptake by four varieties (Indian mustard, sorghum, wheat, and maize) up to $500 \mathrm{ppm}$ showed 100 percent germination and no effect on germination was observed. There was no important decline in germination up to 600 but after that gradual decline was resulted. Germination was observed more in Indian mustard than that of sorghum and wheat. However, result indicated maize germination was maximum as compared to other three crops. In addition, there was no considerable germination was examined at $1000 \mathrm{ppm}$ concentration in Indian mustard, sorghum, wheat, and maize crops (Table 1).

Table 1. Effect of chromium on germination (\%) of different agricultural crops

\begin{tabular}{|c|c|c|c|c|}
\hline \multirow{2}{*}{$\begin{array}{c}\text { Concentrations } \\
(\mathrm{ppm})\end{array}$} & \multicolumn{4}{|c|}{ Germination (\%) } \\
\cline { 2 - 5 } & $\begin{array}{c}\text { Indian } \\
\text { mustard }\end{array}$ & Sorghum & Wheat & Maize \\
\hline Control (0) & 100 & 100 & 100 & 100 \\
\hline 25 & 100 & 100 & 100 & 100 \\
\hline 50 & 100 & 100 & 100 & 100 \\
\hline 100 & 100 & 100 & 100 & 100 \\
\hline 200 & 100 & 100 & 100 & 100 \\
\hline 500 & 100 & 100 & 100 & 100 \\
\hline 600 & 100 & $50 \pm 1.25$ & $75 \pm 1.24$ & 100 \\
\hline 700 & $75 \pm 1.15$ & $25 \pm 1.25$ & $50 \pm 1.25$ & $75 \pm 1.21$ \\
\hline 800 & $50 \pm 1.25$ & $25 \pm 1.13$ & $25 \pm 1.10$ & $50 \pm 1.25$ \\
\hline 900 & $25 \pm 1.25$ & $25 \pm 1.14$ & $25 \pm 1.19$ & $50 \pm 1.25$ \\
\hline 1000 & $5 \pm 1.23$ & $5 \pm 1.19$ & $10 \pm 1.20$ & $10 \pm 1.24$ \\
\hline
\end{tabular}

\subsection{Effect of Cr on Radicle and Plumule length (PL and} RL)

The effect of different concentrations of $\mathrm{Cr}$ on plumule and radicle length of different agricultural crops was examined by treating with different concentrations of $\mathrm{Cr}$. A major reduction was observed in radicle and plumule length under $\mathrm{Cr}$ stress with increasing concentrations. In Indian mustard RL and PL decreased from $6.5 \mathrm{~cm} \& 6.5 \mathrm{~cm}$ (control) to $0.91 \mathrm{~cm} \& 0.80 \mathrm{~cm}(1000 \mathrm{ppm})$. In sorghum the reduction was low as compared to Indian mustard from $2.10 \mathrm{~cm}$ to 0.17 $\mathrm{cm}(\mathrm{RL})$ and $3.80 \mathrm{~cm}$ to $1.76 \mathrm{~cm}$ (PL). The both RL and PL in wheat also declined less than that of both from Indian mustard and sorghum. Result indicated substantial reduction in RL and PL of maize crop (Table 2). 
Table 2. Effect of different concentrations of $\mathrm{Cr}$ on plumule length (PL) and radicle length (RL) of different agricultural crops

\begin{tabular}{|c|c|c|c|c|c|c|c|c|}
\hline \multirow{2}{*}{$\begin{array}{c}\text { Concentrations } \\
(\mathrm{ppm})\end{array}$} & \multicolumn{2}{|c|}{ Indian mustard } & \multicolumn{2}{c|}{ Sorghum } & \multicolumn{2}{c|}{ Wheat } & \multicolumn{2}{c|}{ Maize } \\
\cline { 2 - 9 } & $\mathrm{RL}(\mathrm{cm})$ & $\mathrm{PL}(\mathrm{cm})$ & $\mathrm{RL}(\mathrm{cm})$ & $\mathrm{PL}(\mathrm{cm})$ & $\mathrm{RL}(\mathrm{cm})$ & $\mathrm{PL}(\mathrm{cm})$ & $\mathrm{RL}(\mathrm{cm})$ & PL $(\mathrm{cm})$ \\
\hline Control $(0)$ & $6.5 \pm 2.12$ & $6.5 \pm 0.70$ & $2.10 \pm 1.41$ & $3.80 \pm 2.30$ & $2.90 \pm 0.37$ & $11.75 \pm 0.45$ & $3.75 \pm 0.35$ & $3.25 \pm 3.50$ \\
\hline 25 & $6.1 \pm 2.11$ & $4.75 \pm 0.65$ & $1.90 \pm 1.39$ & $3.66 \pm 2.10$ & $2.67 \pm 0.33$ & $10.70 \pm 0.44$ & $3.59 \pm 0.34$ & $3.20 \pm 3.39$ \\
\hline 50 & $5.67 \pm 2.09$ & $3.25 \pm 0.60$ & $1.40 \pm 1.37$ & $3.45 \pm 1.90$ & $2.45 \pm 0.30$ & $9.65 \pm 0.43$ & $3.45 \pm 0.32$ & $3.15 \pm 3.25$ \\
\hline 100 & $4.98 \pm 2.05$ & $2.50 \pm 0.55$ & $1.10 \pm 1.35$ & $3.10 \pm 1.60$ & $2.21 \pm 0.28$ & $8.60 \pm 0.43$ & $3.30 \pm 0.31$ & $3.10 \pm 3.10$ \\
\hline 200 & $4.85 \pm 2.01$ & $1.96 \pm 0.50$ & $0.99 \pm 1.20$ & $2.98 \pm 1.30$ & $2.10 \pm 0.25$ & $7.55 \pm 0.42$ & $3.09 \pm 0.30$ & $3.05 \pm 2.90$ \\
\hline 500 & $3.66 \pm 1.95$ & $1.88 \pm 0.47$ & $0.79 \pm 1.10$ & $2.78 \pm 0.97$ & $1.91 \pm 0.22$ & $6.75 \pm 0.41$ & $2.93 \pm 0.29$ & $2.80 \pm 2.75$ \\
\hline 600 & $2.80 \pm 1.90$ & $1.67 \pm 0.41$ & $0.58 \pm 0.90$ & $2.55 \pm 0.85$ & $1.78 \pm 0.20$ & $4.90 \pm 0.40$ & $2.85 \pm 0.27$ & $2.55 \pm 2.50$ \\
\hline 700 & $2.65 \pm 1.70$ & $1.33 \pm 0.30$ & $0.47 \pm 0.60$ & $2.37 \pm 0.71$ & $1.59 \pm 0.14$ & $3.85 \pm 0.40$ & $2.78 \pm 0.25$ & $2.39 \pm 2.10$ \\
\hline 800 & $2.61 \pm 1.50$ & $1.10 \pm 0.29$ & $0.35 \pm 0.30$ & $2.10 \pm 0.59$ & $1.40 \pm 0.12$ & $2.99 \pm 0.39$ & $1.90 \pm 0.20$ & $1.55 \pm 1.55$ \\
\hline 900 & $1.51 \pm 0.53$ & $0.90 \pm 0.22$ & $0.27 \pm 0.15$ & $1.98 \pm 0.48$ & $1.10 \pm 0.09$ & $2.55 \pm 0.39$ & $0.9 \pm 0.15$ & $0.10 \pm 0.95$ \\
\hline 1000 & $0.91 \pm 0.08$ & $0.80 \pm 0.04$ & $0.17 \pm 0.07$ & $1.76 \pm 0.37$ & $1.07 \pm 1.04$ & $1.27 \pm 0.38$ & $0.6 \pm 0.12$ & $0.6 \pm 0.10$ \\
\hline
\end{tabular}

Table 3. Effect of alleviators on plumule length (PL) and radicle length (RL) of different agricultural crops

\begin{tabular}{|c|c|c|c|c|c|c|c|c|}
\hline \multirow{2}{*}{ Alleviators } & \multicolumn{2}{|c|}{ Indian mustard } & \multicolumn{2}{c|}{ Sorghum } & \multicolumn{2}{c|}{ Wheat } & \multicolumn{2}{c|}{ Maize } \\
\cline { 2 - 9 } & RL & PL & RL & PL & RL & PL & RL & PL \\
\hline $\begin{array}{c}\text { Control (Cr } \\
\text { solution only) }\end{array}$ & $0.90 \pm 0.07$ & $0.81 \pm 0.03$ & $0.15 \pm 0.07$ & $1.75 \pm 0.35$ & $1.05 \pm 1.03$ & $1.25 \pm 0.35$ & $0.5 \pm 0.17$ & $0.7 \pm 0.18$ \\
\hline $\begin{array}{c}\text { Ammonium } \\
\text { sulphate }\end{array}$ & $3.1 \pm 0.31$ & $2.9 \pm 0.41$ & $2.5 \pm 0.21$ & $2.3 \pm 0.24$ & $2.7 \pm 0.29$ & $2.3 \pm 0.26$ & $2.8 \pm 0.29$ & $2.4 \pm 0.25$ \\
\hline $\begin{array}{c}\text { Calcium } \\
\text { sulphate }\end{array}$ & $4.10 \pm 0.10$ & $3.8 \pm 0.39$ & $3.5 \pm 0.26$ & $3.4 \pm 0.31$ & $3.8 \pm 0.35$ & $3.7 \pm 0.36$ & $3.9 \pm 0.38$ & $3.4 \pm 0.35$ \\
\hline $\begin{array}{c}\text { Calcium } \\
\text { phosphate }\end{array}$ & $4.4 \pm 0.34$ & $3.9 \pm 0.34$ & $3.4 \pm 0.24$ & $4.1 \pm 0.34$ & $3.7 \pm 0.40$ & $3.1 \pm 0.34$ & $4.2 \pm 0.43$ & $3.3 \pm 0.30$ \\
\hline $\begin{array}{c}\text { Potassium } \\
\text { chloride }\end{array}$ & $4.9 \pm 0.52$ & $4.3 \pm 0.40$ & $4.5 \pm 0.44$ & $4.1 \pm 0.41$ & $4.7 \pm 0.43$ & $4.2 \pm 0.42$ & $3.9 \pm 0.39$ & $3.5 \pm 0.37$ \\
\hline Zinc sulphate & $7.2 \pm 0.38$ & $5.9 \pm 0.43$ & $8.7 \pm 0.84$ & $6.9 \pm 0.80$ & $10.6 \pm 0.81$ & $9.0 \pm 0.87$ & $13.6 \pm 0.89$. & $12.5 \pm 0.91$ \\
\hline
\end{tabular}

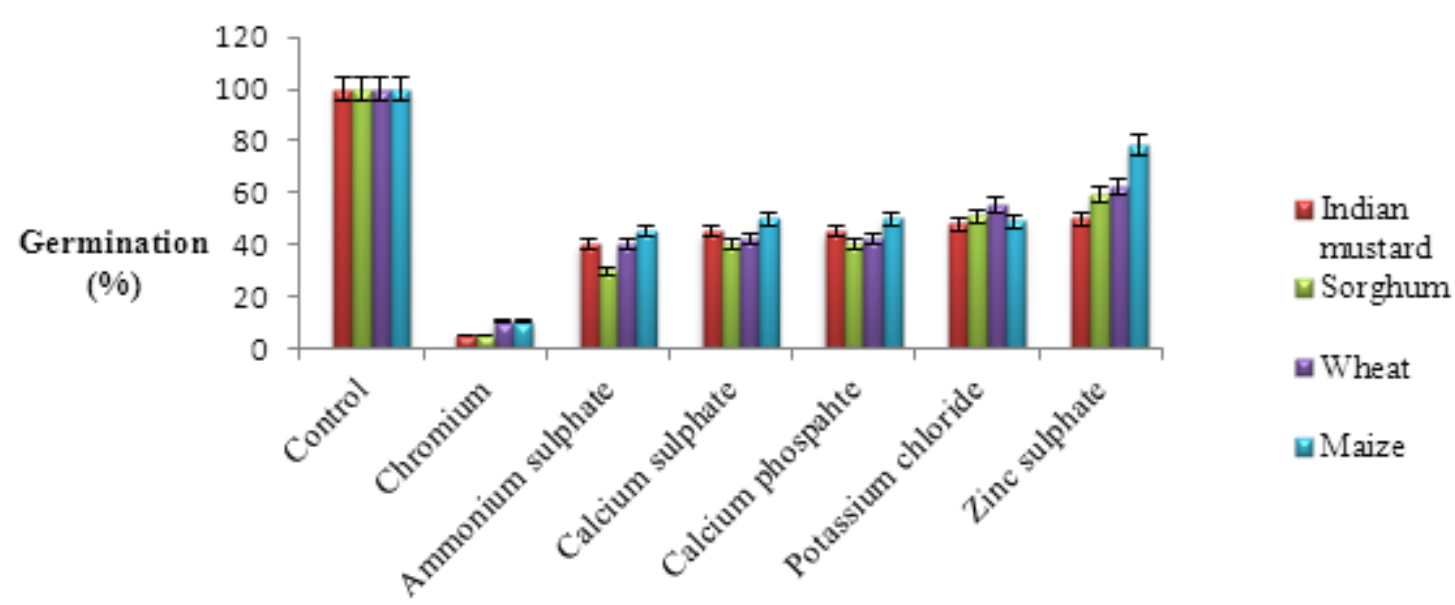

Figure 1. Effect of different alleviators in contrast to chromium on germination of agricultural crops

\subsection{Effect of Alleviators in Reducing Chromium Toxicity}

Results revealed that different alleviators significantly reduced the chromium toxicity and promoted germination in agricultural crops. Effects of alleviators on radicle and plumule length of different agricultural crops (Indian mustard, sorghum, wheat, and maize) were monitored. Result showed noteworthy improvement in germination after treatment with alleviators. All four alleviators have indicated different results of toxicity reduction. From these five, zinc sulphate proved to be more beneficial in germination. Alleviators improved much germination than that of 1000 ppm inhibition, as Indian mustard RL and PL improved from $0.9 \mathrm{~cm} \& 0.81 \mathrm{~cm}(1000 \mathrm{ppm})$ to $7.2 \mathrm{~cm} \& 5.9 \mathrm{~cm}$ (zinc sulphate) respectively. In other three crops also, zinc sulphate inhibited the toxicity of chromium and allowed to germinate both radicle and plumule. Maize indicated RL and PL were enlarged from $0.5 \mathrm{~cm} \& 0.7 \mathrm{~cm}(1000 \mathrm{ppm})$ to 13.6 
$\mathrm{cm} \& 12.5 \mathrm{~cm}$ (zinc sulphate) respectively (Table 3 ). Observations indicated the gradual increase in germination percentage in crops by applying alleviators dose in following order: ammonium sulphate $<$ calcium sulphate $<$ calcium phosphate $<$ potassium chloride $<$ zinc sulphate. Among crops maximum improvement in germination was noticed in maize by alleviators treatment (Figure 1). Graphical representation of four crops and alleviators used clearly depicted the percentage reduction in all crops and their RL \& PL (Figure 2).
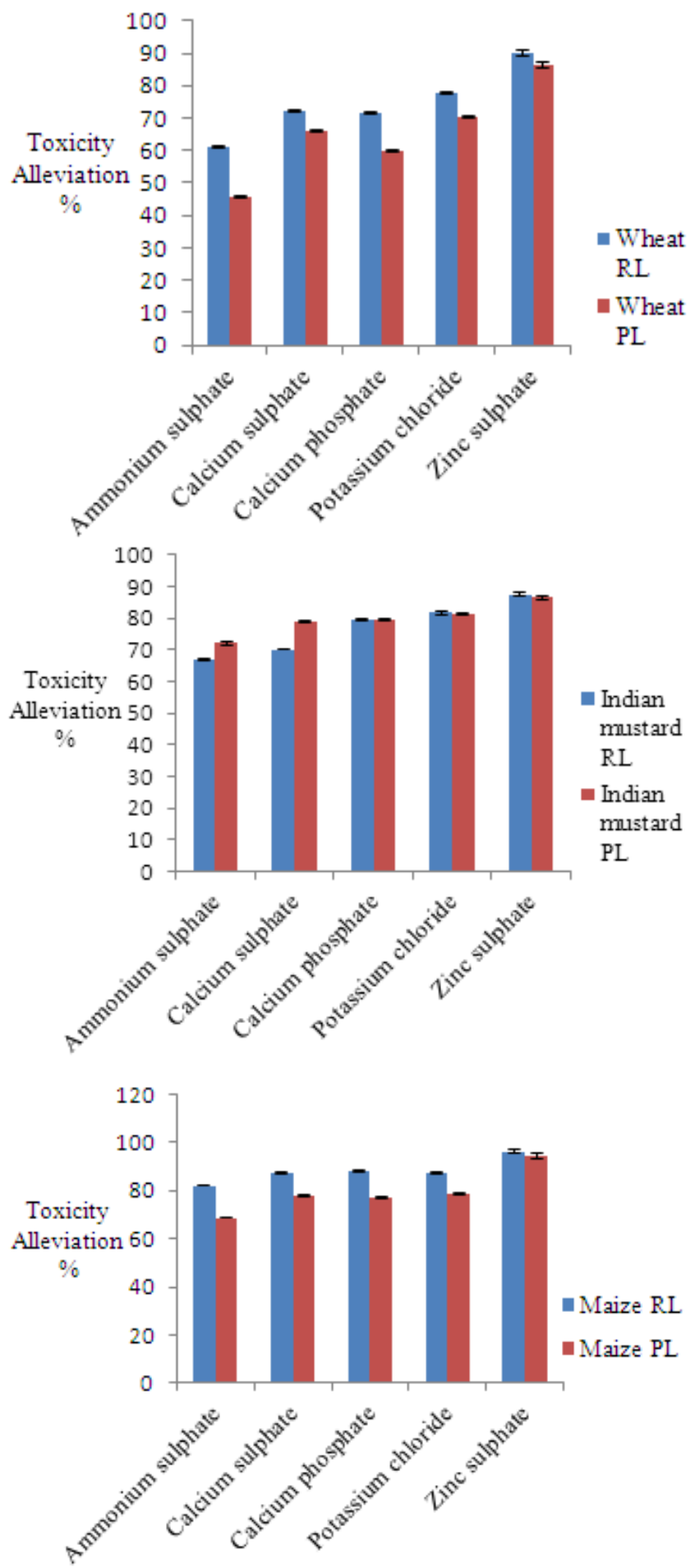

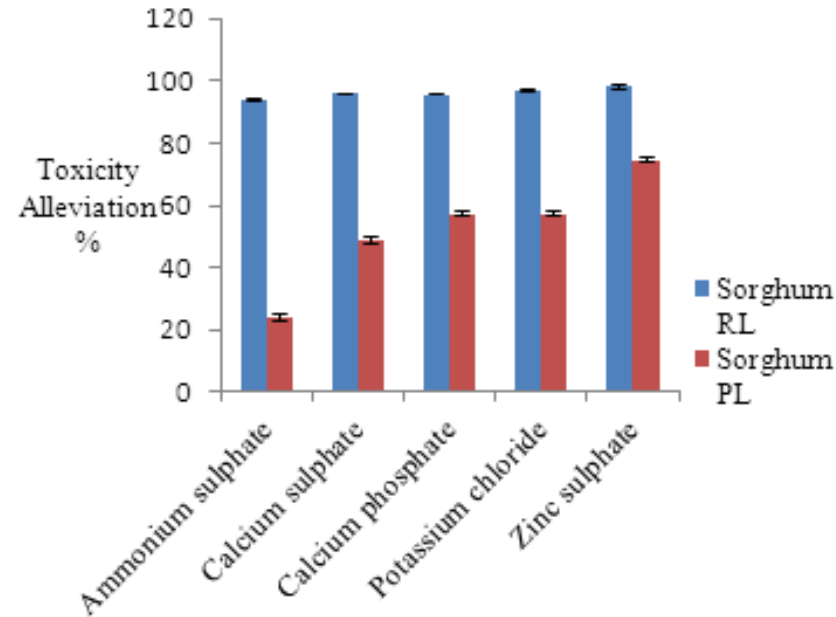

Figure 2.Chromium toxicity alleviation by using different alleviators in radicle and plumule length of common agricultural crops; a. Wheat; $b$. Indian mustard; c. Maize; d. Sorghum

\section{Discussion}

Present study deals with different agricultural crops (wheat, maize, Indian mustard, sorghum) were exposed to high $\mathrm{Cr}$ concentrations and various alleviators (ammonium sulphate, calcium sulphate, calcium phosphate, potassium chloride, zinc sulphate) were used to alleviate chromium toxicity. Higher concentration of $\mathrm{Cr}$ can cause harmful toxicological effects to plants; causes reduction in growth, interferes with photosynthesis and respiration, affect root and shoot length, stomatal conductance and rate of transpiration [9].

Seed germination is sensitive stage of plant life and changes in internal conditions and environmental parameters affect the seed germination. Higher concentrations of $\mathrm{Cr}$ are proved to toxic for seed germination. Seed germination inhibition seemed to be first step in seed defense mechanism when environmental conditions are severe [19]. In our study, it was proved that more than $500 \mathrm{ppm} \mathrm{Cr}$ is toxic in germination of seeds. As many studies reported that concentration (500 ppm) of chromium affected germination in wheat and sorghum [10], $40 \mathrm{ppm} \mathrm{Cr}$ caused 50\% reduced seed germination in alfalfa and $57 \%$ decline in sugarcane buds was observed at $80 \mathrm{ppm} \mathrm{Cr}$ [15]. The inhibition of germination rate that was observed at high chromium concentration could be as a result of depression of oxygen uptake and physiological disturbance in mobilization of reserve food materials of seeds. The inhibition ability of chromium in seeds caused immobilization of food, reduction in oxygen uptake, physiological disturbances [5].

The effects of amendments for the evaluation of chromium toxicity on higher crops have been documented [5]. Cr toxicity imposed competition of food with other nutrient cations due to which plumule and radicle length reduces, zinc sulphate decreased this competition by resulting improvement in germination. The alleviators addition would enhance plant tolerance to toxic metals 
through reducing the uptake and translocation of heavy metals like chromium [20], [4], [6]. Study reported NaHS and $\mathrm{H}_{2} \mathrm{~S}$ are significant in reducing chromium toxicity in barley [16]. Study inferred that under Cr stress alleviators application could effectively enhance the defensive mechanism against oxidative stress induced by $\mathrm{Cr}$ toxicity in crops seedlings. The toxicity reduction in germination caused through inhibiting the uptake and translocation of $\mathrm{Cr}$ in seeds.

\section{Conclusions}

Chromium caused reduction in germination of seeds of different crops but alleviators addition proved improved germination. It was concluded from the present study that the use of alleviators (ammonium sulphate, calcium sulphate, calcium phosphate, potassium chloride, zinc sulphate) reduced chromium toxicity. The $1000 \mathrm{ppm}$ chromium significantly inhibited germination, plumule and radicle length while using even 200 ppm alleviators hindered toxicity in crops; wheat, Indian mustard, sorghum, and maize. Among all the alleviators zinc sulphate considerably enhanced germination of maize up to $90 \%$ and sorghum and wheat up to $70 \%$.

\section{REFERENCES}

[1] A. K. Shanker, C. Cervantes, H. Loza-Tavera, S.Avudainayagam. Chromium toxicity in plants, Journal of Environment International, Vol.31, 739-53, 2005.

[2] B. Duarte, V. Silva, I. Cacador. Hexavalent chromium reduction, uptake and oxidative biomarkers in Halimione portulacoides, Journal of Ecotoxicological and. Environmental Safety, Vol.83, 1-7, 2012.

[3] B. K. Dube, T. Kamlesh, J. Chatterjee, C. Chatterjee. Excess chromium alters uptake and translocation of certain nutrients in citrullus, Journal of Chemosphere, Vol.53, 1147-1153, 2003.

[4] C. C. Nwugo, A. J. Huerta. Silicon-induced cadmium resistance in rice (Oryza sativa), Journal of Plant Nutrition and Soil Science, Vol. 171, 841-848, 2008.

[5] C. Chigbo, L. Batty. Effect of combined pollution of chromium and benzo (a) pyrene on seed growth of Loliumperenne, Journal of Chemosphere, Vol.90, 164-169, 2013.

[6] C. Kaya, A. L. Tuna, O. Sonmez, F. Ince, D. Higgs. Mitigation effects of silicon on maize plants grown at high zinc, Journal of Plant Nutrition, Vol.32, 1788-1798, 2009.

[7] D. Sayantan, Shardendu. Amendment in phosphorus levels moderates the chromium toxicity in Raphanus sativus L. as assayed by antioxidant enzymes activities, Journal of Eco-toxicological and. Environmental Safety, Vol. 95, 161-170, 2013.

[8] F. T. Davies, J.D. Puryear, R. J. Newton, J. N. Egilla, J.A.S.
Grossi. Mycorrhizal fungi increase chromium uptake by sunflower plants: influence on tissue mineral concentration, growth, and gas exchange, Journal of Plant Nutrition, Vol. 25, 2389-2407, 2002.

[9] H. P. Singh, P. Mahajan, S. Kaur, D. R. Batish, R. K. Kohli. Chromium toxicity and tolerance in plants.Jouranl of Environemental Chemistry Letters, 1-26, 2013.

[10] J. Lopez-Luna, M. Gonzalez-Chavez, F. Esparza-Garcia, R. Rodriguez-Vazquez. Toxicity assessment of soil amended with tannery sludge, trivalent chromium and hexavalent chromium, using wheat, oat and sorghum plants. Journal of Hazardous Materials, Vol. 2, 829-834, 2009.

[11] J. Namiesnik, A. Rabajczyk. Speciation analysis of chromium in environmental samples, Journal of Critical Reviews in Environmental Science and Technology, 2012. Vol. 42, 32777, 2012.

[12] L. Somova, N. Pechurkin. The influence of microbial associations on germination of wheat seedsand growth of seedlings under impact of zinc salts, Journal of Advances in Space Research, Vol. 8, 1224-1228, 2009.

[13] O. Munzuroglu, H. Geckil. Effects of metals on seed germination, root elongation, and coleoptile and hypocotyl growth in Triticum aestivum and Cucumis sativus, Journal of Archieves of Enviroenmental Contamination and Toxicology, Vol. 2, 203-213, 2002.

[14] P. Sundaramoorthy, A. Chidambaram, K. S. Ganesh, P. Unnikannan, L. Baskaran. Chromium stress in paddy:(i) Nutrient status of paddy under chromium stress;(ii) Phytoremediation of chromium by aquatic and terrestrial weeds, CR Biol Journal, Vol. 8, 597-607, 2010.

[15] R. Jain, S. Srivastava, V. K. Madan. Influence of chromium on growth and cell division of sugarcane. Indian,Journal of Plant Physiology, Vol. 5, 228-31, 2000.

[16] S. Ali, M.A. Farooq, S. Hussain, T. Yasmeen, G.H. Abbasi, G. Zhang. Alleviation of chromium toxicity by hydrogen sulfide in barley, Journal of Environmental Toxicology and Chemistry, Vol. 10, 2234-2239, 2013.

[17] S. K. Dey, P. P. Jena, S. Kundu. Antioxidative efficiency of Triticum aestivum L. exposed to chromium stress, Journal of Environemntal Biology, Vol. 4, 539-544, 2009.

[18] S. K. Pandey, S. K. Pandey, M. Pandey, Z. Town. Germination and seedling growth of field pea Pisum sativum Malviya Matar-15 (HUDP-15) and Pusa Prabhat (DDR-23) under varying level of copper and chromium, American Journal of Medical Sciences, Vol. 3, 28-40, 2008.

[19] W. Li, M. A. Khan, S. Yamaguchi, Y. Kamiya. Effects of heavy metals on seed germination and early seedling growth of Arabidopsis thaliana, Journal of Plant Growth Regulation, Vol. 1, 45-50, 2005

[20] X. H. Sh, C. C. Zhang, H. Wang,. F. S. Zhang. Effect of Si on the distribution of $\mathrm{Cd}$ in rice seedlings, Journal of Plant Soil, Vol. 272, 53-60, 2005b.

[21] X. F. Han, S. B. B. Maruthi, L.D. Monts, Y. Su. Phytoavailability and toxicity oftrivalent and hexavalent chromium to Brassica juncea, New Phytologist, Vol. 162, 489-499, 2004.

[22] Z. Fan-rong, Z. Fu-sheng, Q. Bo-yin, O. Younan, W. Feibo, Z. Guoping. Alleviation of chromium toxicity by silicon 
addition in rice plants, Journal of Agricultural Sciences in China, Vol. 8, 1188-1196, 2011.
[23] R. G. Steel, J. H. Torrie. Principles and procedures of statistics, a biometrical approach, McGraw-Hill Kogakusha, Ltd., Vol. 2. 